See Article page e129.

\section{Commentary: Ascending aortic aneurysms: A marker for freedom from atherosclerosis and a milestone in our understanding}

\author{
John G. Augoustides, MD, FASE, FAHA
}

Ascending aortic aneurysms have important clinical complications. ${ }^{1,2}$ The absence of atherosclerosis in their genesis compared with the thoracoabdominal aorta has been highlighted in an intriguing report by Weininger and colleagues. $^{3}$ This atherosclerotic heterogeneity in the thoracic aorta may be due to differences in their embryologic origins. ${ }^{3-5}$ The ascending aorta and aortic arch are derived from the embryonic neural crest, whereas the thoracoabdominal aorta is derived from embryonic somites and splanchnic mesoderm. ${ }^{4,5}$

The systematic observations by Weininger and colleagues ${ }^{3}$ have demonstrated that atherosclerotic markers such as calcium scores, carotid intima-media thickness, and coronary artery disease are conspicuously attenuated in patients with ascending aortic aneurysms. ${ }^{3-5}$ In an elegant case-control analysis, this group has now demonstrated that elevated low-density lipoprotein levels are unlikely to be associated with ascending aortic aneurysms. ${ }^{3}$ Given that elevated low-density lipoprotein levels predict atherosclerosis, this inverse relationship is consistent with their prior published observations pointing to freedom from atherosclerosis in this aortic phenotype. . $^{3-5}$

Although this association is indeed a "silver lining" for these patients, could it also advance our understanding and management of thoracic aortic aneurysms? First,

\footnotetext{
From the Cardiovascular and Thoracic Section, Department of Anesthesiology and Critical Care, Perelman School of Medicine, University of Pennsylvania, Philadelphia, Pa.

Financial Support: Institutional.

Disclosures: The author reported no conflicts of interest.

The Journal policy requires editors and reviewers to disclose conflicts of interest and to decline handling or reviewing manuscripts for which they may have a conflict of interest. The editors and reviewers of this article have no conflicts of interest.

Received for publication Sept 27, 2021; revisions received Sept 27, 2021; accepted for publication Sept 28, 2021; available ahead of print Sept 30, 2021.

Address for reprints: John G. Augoustides, MD, FASE, FAHA, Cardiovascular and Thoracic Section, Department of Anesthesiology and Critical Care, Dulles 680, HUP, 3400 Spruce St, Philadelphia, PA 19104-4283 (E-mail: yiandoc@hotmail. com).

J Thorac Cardiovasc Surg 2022;163:e133-4

$0022-5223 / \$ 36.00$

Copyright (C) 2021 by The American Association for Thoracic Surgery

https://doi.org/10.1016/j.jtcvs.2021.09.042
}

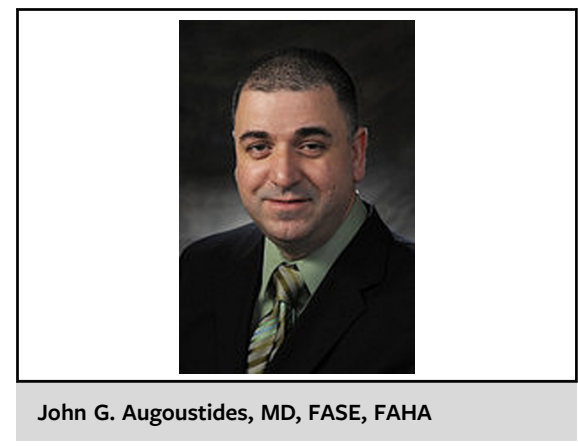

CENTRAL MESSAGE

Ascending aortic aneurysms are unlikely to be associated with atherosclerosis. This phenotypic relationship may yield important clues for more personalized therapeutic options for our patients.

further trials could confirm this association and examine whether it is also applies to the aortic arch, given that it shares a common embryonic origin with the ascending aorta. $^{4-6}$

Second, this observation could be integrated with the expanding horizons in hereditary thoracic aortic disease. ${ }^{7}$ This disease group offers opportunities for multiple important pathophysiologic and therapeutic breakthroughs. ${ }^{7}$ The knowledge gaps in this setting include underlying genotypes in nonsyndromic presentations and effective medical therapies in non-Marfan conditions. The observation by Weininger and colleagues ${ }^{3}$ could inform future genomic investigation with detailed consideration of relevant nonatherogenic genotypes. ${ }^{3,7}$ Their observation could also direct searches for pharmacologic targets through further molecular investigations of ascending aortic aneurysms, including the role of endothelial dysfunction. . $^{3,7,8}$

Third, because ascending aortic aneurysms are part of the aortopathy associated with bicuspid aortic valve disease, the observations by Weininger and colleagues ${ }^{3}$ also could be explored in this context. ${ }^{2,3,7,8} \mathrm{~A}$ recent international consensus has defined 3 presentations for the bicuspid aortic valve (partial-fusion type, fused type, 2-sinus type) and 3 presentations for the associated aortopathy (root, ascending, and extended phenotypes). ${ }^{3}$ Does the risk for associated atherosclerosis vary significantly across this phenotypic 
spectrum? Could this variation inform our understanding of the embryology of the bicuspid aortic valve? ${ }^{9,10}$ Could this possible variation in atherosclerotic risk across the phenotypes for valve and proximal aorta stimulate a more personalized approach to medical and surgical therapy? ${ }^{11,12}$ The thoughtful interpretation of variations in lipid metabolism and atherosclerotic risk across the bicuspid aortic valve spectrum could provide important molecular, cellular, and morphological perspectives to foster more precise and personalized care for our patients. ${ }^{10-13}$

In conclusion, Weininger and colleagues ${ }^{3}$ are to be congratulated for highlighting the relative absence of atherosclerosis in ascending aortic aneurysms and its importance as a milestone in our understanding. It is likely that future advances in thoracic aortic aneurysms will be significantly influenced by this observation.

\section{References}

1. Guo MH, Appoo JJ, Hendry P, Maters R, Chy MWA, Ouzounian M, et al. Knowledge, attitudes, and practice preferences in the surgical threshold for ascending aortic aneurysm among Canadian cardiac surgeons. J Thorac Cardiocasc Surg. February 1, 2021 [Epub ahead of print].

2. Michelena HI, Della Corte A, Evangelista A, Maleszewski JJ, Edwards WD, Roman MJ, et al. International consensus statement on nomenclature and classification of congenital bicuspid aortic valve and its aortopathy for clinical, surgi- cal, interventional and research purposes. J Thorac Cardiovasc Surg. 2021;162: e383-414.

3. Weininger G, Ostberg N, Shang M, Zafar M, Ziganshin BA, Liu S, et al. Lipid profiles help to explain protection from systemic atherosclerosis in patients with ascending aortic aneurysm. J Thorac Cardiovasc Surg. 2022;163: e129-32.

4. Kuivaniemi H, Ryer E, Elmore JR, Tromp G. Understanding the pathogenesis of abdominal aortic aneurysms. Expert Rev Cardiovasc Ther. 2015;13:975-87.

5. Tromp G, Kuvaniemi H, Hinterseher I, Carey DJ. Novel genetic mechanisms for aortic aneurysms. Curr Atheroscler Rep. 2010;12:259-66.

6. Czerny M, Schmidki J, Adler S, van der Berg JC, Bertoglio L, Carrel T, et al. Current options and recommendations for the treatment of thoracic aortic pathologies involving the aortic arch: an expert consensus document of the European Association for Cardiothoracic Surgery (EACTS) and the European Society for Vascular Surgery (ESVS). Eur J Vasc Endovasc Surg. 2019;57: 165-98.

7. Roman MJ, De Backer J. Hereditary thoracic aortic disease: how to save lives. J Thorac Cardiovasc Surg. February 1, 2021 [Epub ahead of print].

8. Antequera-Gonzalez B, Martinez-Micaelo N, Alegret JM. Bicuspid aortic valve and endothelial dysfunction: current evidence and potential therapeutic targets. Front Physiol. 2020;11:1015.

9. Gleason TH. Commentary: bicuspid aortic valve consensus or quandary? J Thorac Cardiovasc Surg. 2021;162:801-2.

10. Soto-Navarrete MT, Lopez-Untu MA, Duran AC, Fernandez B. Embryonic development of bicuspid aortic valves. Prog Cardiovasc Dis. 2020;63:407-18.

11. Orozco-Sevilla V, Coselli JS. Commentary: Parley at the summit. J Thorac Cardiovasc Surg. 2021;162:799-800.

12. Roselli EE. Commentary: bicuspid aortic valve and experts' consensus: more than the sum of its parts. J Thorac Cardiovasc Surg. 2021;162:798-9.

13. Magni P. Bicuspid aortic valve, atherosclerosis, and changes in lipid metabolism: are there pathological molecular links? J Mol Cell Cardiol. 2019;129:231-5.

\section{Commentary: Current understanding of the role of atherosclerosis in aneurysmal disease is incomplete}

\section{Dawn S. Hui, MD, and Andrea J. Carpenter, MD, PhD}

The group at Yale has extensive experience with treatment of aortic disease and has widely published on the topic. In

\footnotetext{
From the Department of Cardiothoracic Surgery, Joe R. and Teresa Lozano Long School of Medicine, UT Health San Antonio, San Antonio, Tex.

Disclosures: The authors reported no conflicts of interest.

The Journal policy requires editors and reviewers to disclose conflicts of interest and to decline handling or reviewing manuscripts for which they may have a conflict of interest. The editors and reviewers of this article have no conflicts of interest.

Received for publication Oct 5, 2021; revisions received Oct 5, 2021; accepted for publication Oct 7, 2021; available ahead of print Oct 12, 2021.

Address for reprints: Andrea J. Carpenter, MD, PhD, Department of Cardiothoracic Surgery, Joe R. and Teresa Lozano Long School of Medicine, 7703 Floyd Curl Dr, MC 7841, San Antonio, TX 78015 (E-mail: carpentera2@uthscsa.edu).

J Thorac Cardiovasc Surg 2022;163:e134-5

$0022-5223 / \$ 36.00$

Copyright (c) 2021 by The American Association for Thoracic Surgery

https://doi.org/10.1016/j.jtcvs.2021.10.008
}

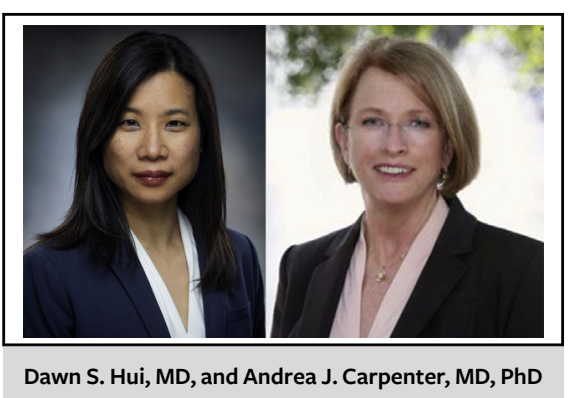

CENTRAL MESSAGE

A propensity-matched analysis demonstrates an inverse relationship between LDL levels and odds of ascending thoracic aortic aneurysm, but the implication for statin use remains unknown. 